\title{
Comunicación, cultura y música
}

\section{Análisis semiótico y discursivo de los grupos musicales "La Grupa" y "Curare" como base para la construcción de la identidad mestiza ecuatoriana}

Javier López Narváez*

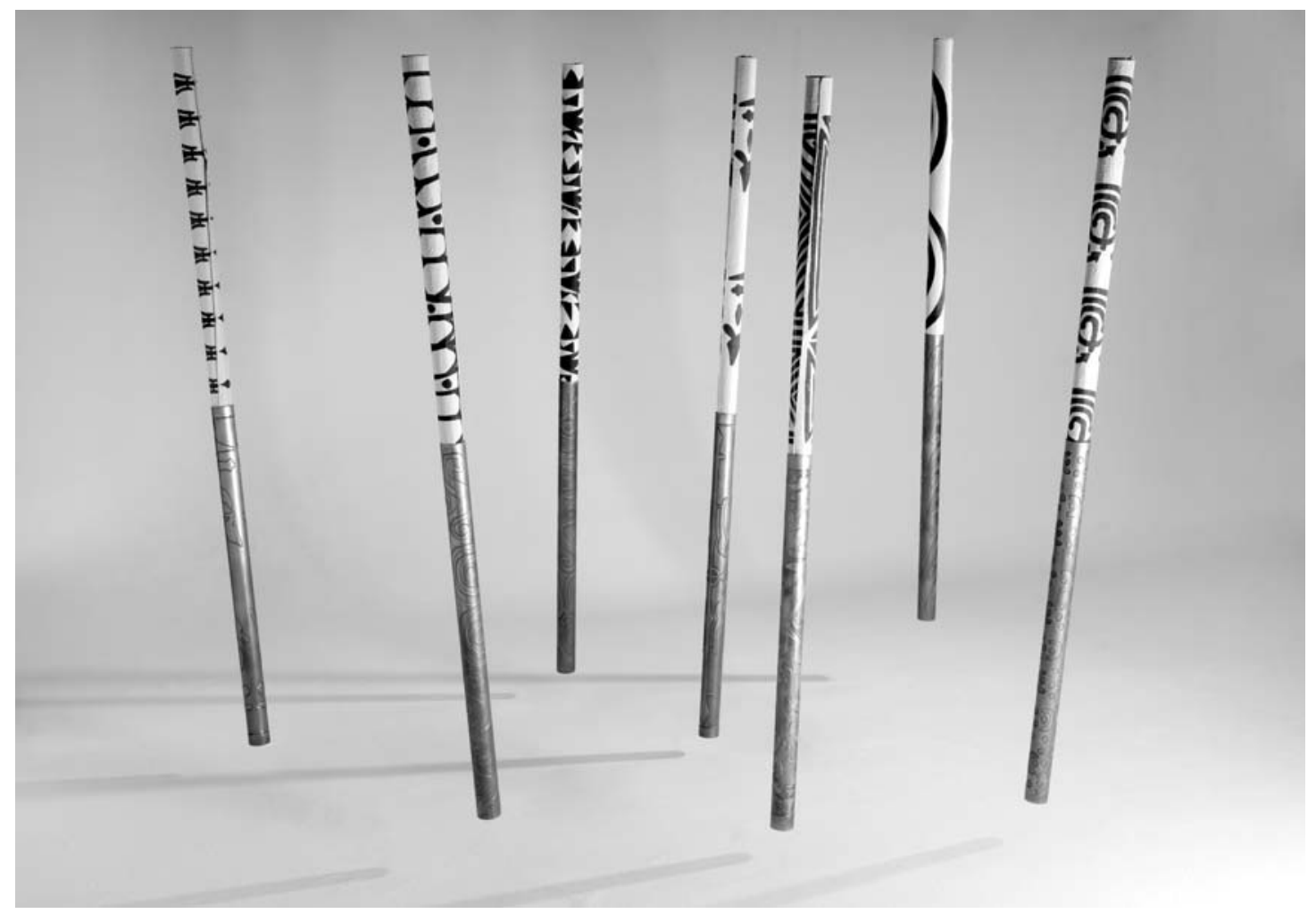

Mi escencia libro

La sociedad ecuatoriana es esencialmente mestiza. Las particulares circunstancias histórico-sociales de este mestizaje han dado como resultado la pérdida de la noción de pertenencia a una cultura determinada proceso $\mathrm{cu}$ - ya sintomatología puede encontrarse en algunas prácticas individuales tendientes a la negación y al ocultamiento de una realidad cultural que, se expresa en el actuar social de los ecuatorianos.

\footnotetext{
* Licenciado en Comunicación Social con especialidad en Desarrollo por la UPS - Quito.
} 
Dado que la cultura existe como resultado del actuar social de un pueblo y se manifiesta en toda la producción simbólica de dicha sociedad, la cultura mestiza existe no sólo como el resultado de un hecho histórico de mezcla genética, sino, además, como el producto del encuentro y la confrontación de dos formas diferentes de percibir la realidad y de entender el mundo; proceso que, hoy por hoy, se complementa necesariamente con los efectos culturales de los medios de comunicación masiva cuyo continuo bombardeo discursivo mantiene una dinámica que permite establecer contactos e intercambios a larga distancia, pero en tiempo real, con otras formas de ver el mundo, es decir, con otro tipo de culturas. Tales culturas, en la actualidad, se han convertido en parte integral del mestizaje, que en el caso ecuatoriano ha resultado en una sociedad única dentro del contexto de América Latina y el mundo.

La música, al igual que todas las manifestaciones artísticas, es un objeto cultural en sí mismo, un elemento simbólico cargado de significados, y se constituye en algo que comunica, dice algo acerca de la sociedad en cuyo seno fue concebido, lleva en sí mismo un cúmulo de significados sociales. Al comunicar, lo hace también en una dimensión cultural.

Resulta evidente, entonces, que una manera objetiva de aproximarse a una sociedad-cultura determinada es deconstruyendo el mensaje implícito en la música en cuyo contexto se produce; entendiendo por música, en este caso, además de a un sistema de timbres y sonidos temperados, ordenados en el tiempo y en el espacio, a todo el proceso de producción, circulación y consumo de tales sonidos, a los textos que los pueden acompañar y al resto de elementos culturales que complementan la experiencia musical, tales como: soportes de fijación (análogos y digitales), complementos gráficos, vestuario de los ejecutantes, puesta en escena, uso de espacios, etc. El objetivo de este trabajo es analizar el mensaje implícito en la música de los grupos musicales "La Grupa" y "Curare", grupos quiteños de Hardcore y pop-rock respectivamente, en el contexto del grupo mestizo ecuato- riano y el lugar que ocupa en el actual proceso de globalización.

La comunicación humana es un proceso sumamente complejo, que, lejos de la mera transmisión y percepción de ciertos estímulos que determinan patrones de comportamientos preestablecidos, depende de las mediaciones a las cuales responden los sujetos de la comunicación (actores), del contexto en el que se desenvuelven, de su propia historia, personal o grupal, etc. Para comprender el campo de la comunicación en el ámbito social, es necesario entenderlo esencialmente como una relación compleja, establecida entre dos o más sujetos, ya sean éstos individuales o colectivos, los cuales, al decir de Rosa María Alfaro, "se interpelan intersubjetivamente". De ello resulta todo un proceso de construcción individual a partir de dicha interpelación que, a nivel social, deviene en lo que nosotros entendemos como cultura.

En lo referente a la música, la circunstancia de que el producto sea tratado como mercancía y esté dirigido hacia grupos específicos de consumo, hace que los perceptores - oyentes, consumidores de música- se encuentren, en su mayoría, en una constante actitud de docilidad, lo cual los vuelve vulnerables y propensos a actuar en función de lo que tal mensaje les indique.

La cultura no es sólo la producción material de una sociedad. La cultura, en última instancia, es la sociedad misma definida a través de su producción material. De ahí que las formas de ser, de actuar y de entender el mundo determinan y moldean a la cultura del mismo modo que la cultura determina y moldea a los individuos.

Los procesos que se generan en torno a la cultura a través de los mass media son, hoy en día, procesos de "racionalización del consumo"; "lo que preocupa hoy al capitalismo es la producción de signos e imágenes", y esos signos e imágenes son consumidos por la inmensa mayoría de personas alrededor del mundo entero.

Es ahí cuando se desterritorializa la cultura, pues las imágenes producidas por los medios generan una particular forma de ver la vida y de- 
terminados modelos o estándares de vida; crean nuevas materialidades tangibles e intangibles cuyo resultado es una especie de cultura global a la que todos aspiran.

En la práctica, mientras al interior de los territorios se refuerza la localidad, tanto ante el cotidiano actuar de los individuos como por la búsqueda de una identidad local comercializable a través de la diferencia, por otro lado opera la cultura global que generan los medios, dando como resultado una mezcla de ambas que la postre determina la diferencia local frente a la tendencia homogenizadora.

Los grupos "Curare" y "La Grupa" son un claro ejemplo de esto. Mediante la fusión de elementos culturales diversos - música del folklore andino, música afroecuatoriana, rock anglosajón, funk, jazz, etc.— reflejan la particularidad de lo local, entendido como el territorio ecuatoria-

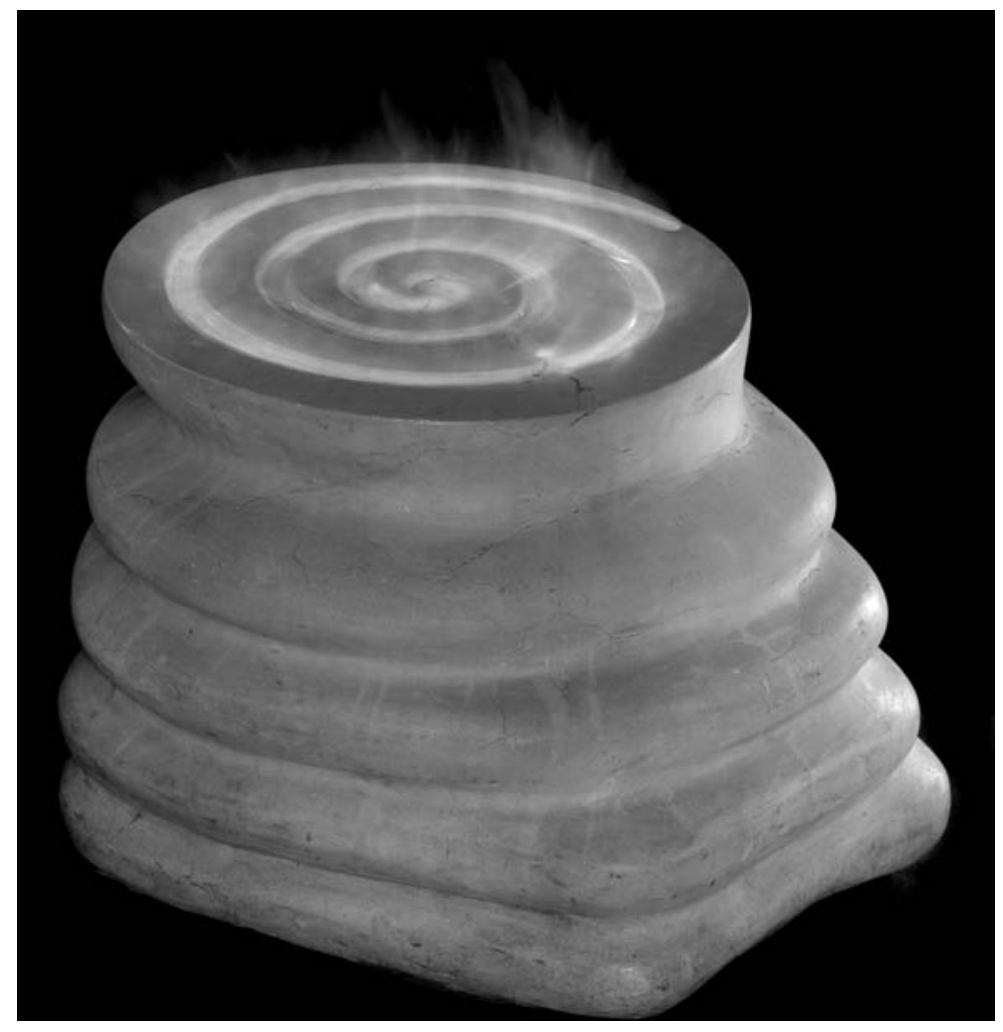

Oráculo no. Y más local aún, si tenemos en cuenta que el sector cultural que realmente está caracterizado por esta hibridación es el mestizo.

El discurso musical es un conjunto complejo de actos musicales, lingüísticos y visuales simultáneos e interrelacionados y que, tal como lo afirma Wodak, significan un ámbito de la práctica social a la vez que se corresponden directamente con la sociedad dentro de la cual aparecieron, afectándola directamente para llegar incluso a modificarla. El discurso musical, en esencia, está formado por cuatro elementos básicos: la música propiamente dicha, es decir, el mensaje musical a nivel semántico; las connotaciones que existen detrás de ese mensaje musical, es decir, los niveles de connotación; el mensaje lingüístico, formado por las letras de las canciones, si las hubiere, y por lo que expresan los músicos de manera verbal o escrita en los ámbitos que oficialmente acompañan al mensaje musical (entrevistas, conciertos, ruedas de prensa, mensajes escritos en discos, etc.); y el mensaje visual, formado por toda la parte gráfica que acompaña a la música (portadas y gráficos de los discos, fotografías, afiches, etc.) así como por otros elementos visuales que ayudan para la contextualización, tales como el vestuario, la presentación física, la apariencia personalizada de los instrumentos musicales, etc.

Un discurso gira en torno a un tema. Más allá de los temas individuales de los que trate cada canción de "Curare" y "La Grupa", la música de ambas bandas, en conjunto, gira en torno al tema del mestizaje ecuatoriano. De hecho, la música de ambas bandas puede ser catalogada como "música mestiza" puesto que es el resultante cultural de una mezcla de distintas visiones de ver el mundo. A ello apunta, en última instancia, la autodefinición de la música de $\mathrm{Cu}$ rare como "longo metal", y la de "La Grupa" como "rock tricolor".

La música es un lenguaje a través del cual es posible articular varios tipos de discursos, y por tanto, se puede establecer comunicación a través de ella. 
$\mathrm{Al}$ ser la música un lenguaje, es posible explotarla como tal para ampliar sus alcances en materia de comunicación.

Hasta hoy, la música ha sido vista nada más que como un elemento de entretenimiento, diversión y esparcimiento.

$\mathrm{Al}$ admitir que la música es un lenguaje con características y alcances comunicativos muy amplios, nos damos cuenta de que la idea de la música como mero entretenimiento implica reducir las posibilidades que ella ofrece.

Es necesario volver a insistir en el siguiente punto: cuando hablamos de música, no nos referimos solamente a los sonidos que la conforman, sino que hemos ampliado el concepto hacia todo el proceso de producción, circulación y consumo que envuelve a la música.

Aun cuando, al definir en el primer capítulo a la música como lenguaje no podemos negar que todo el actuar social que se genera alrededor de ella tiene una carga comunicativa muy grande que complementa en gran medida al discurso estrictamente musical.

Entonces, para poder aprovechar al máximo las posibilidades y los alcances comunicativos de la música hay que tenerla en cuenta en otros planos además del sonido: la música como mercancía, la música como producto cultural, la música como espectáculo, la música como generador y trasmisor de estereotipos, etc.

Además, se debe tener en cuenta que el mensaje que se comunica a través de la música siempre va a estar complementado con una parte gráfica y visual de la cual no se puede desentender, que va desde la forma de vestir de los músicos, hasta los dibujos y la parte gráfica que suele acompañar a los discos, afiches, conciertos, etc.

Podemos poner un par de ejemplos bastante claros referidos a nuestro tema. En el caso de "Curare", el logotipo del grupo usado como portada de su álbum "Radical Acción", muestra a dos serpientes que se unen a través de sus colas enroscadas entre sí, las cuales se abren en una serie de cintas de tejidos con motivos indígenas, dos de las cuales muestran los brazos de una gui- tarra y un bajo respectivamente; mientras que la cinta central se convierte en una quena cuyos huecos se encuentran adornados cada uno con un dibujo de una hoja de marihuana. La parte delantera de las serpientes encierran el nombre de la banda - Curare - escrito en rojo. Todo en un fondo negro.

En ese logotipo está todo: en las serpientes, una verde y otra roja, está contenido el sentido nacional del grupo al integrar el elemento oriental de la selva; además, encierra el contenido del nombre del grupo, ya que la palabra "curare" es la que denomina a un veneno que se usa en las selvas del oriente para envenenar las flechas de los nativos.

En las cintas se encuentra contenida toda la idiosincrasia andina, aquello que nos suele representar en el extranjero. Imposible evitar la referencia a los textiles otavaleños y su amplia presencia en el mundo entero.

En los instrumentos está el elemento de la fusión: la guitarra y el bajo eléctrico junto a una quena; el encuentro de dos formas de ver el mundo en una sola. Y en el fondo la mezcla de colores, el rojo sangre del nombre y el negro del fondo hacen referencia al rock metal.

Como podemos ver, basta con hacer una observación superficial del logotipo de "Curare", para comprender de qué va su música, incluso antes de escucharla.

Con el grupo "La Grupa”, el diseño de la portada de su disco "Homónimo" es mucho más decidor en lo que se refiere a la identidad: se trata de un mapa en alto relieve del Ecuador.

Lo importante de reconocer a la música como un lenguaje independiente es saber aprovechar sus alcances comunicativos de la mejor manera posible. A partir de esta idea se pueden organizar talleres, o grupos musicales cuyo fin específico sea el de la investigación musical en su dimensión netamente comunicativa. De ahí a la estructuración de estrategias comunicativas a través de la música hay un solo paso.

Por lo tanto, la idea del presente trabajo ha sido la de dejar abonado el terreno de la in- 
vestigación, con un sustento teórico de base, para que se puedan desarrollar futuros proyectos con estas finalidades.

\section{Mestizaje y música en el Ecuador}

En nuestro caso particular del continente americano, se entiende como mestizo al individuo que pertenece al grupo étnico surgido a partir de la mezcla del grupo indígena latinoamericano con el español que llegó a nuestras tierras desde finales del siglo XV. En el Ecuador, la mayor parte de la población es mestiza, desde el punto de vista étnico-fenotípico.

Debido a la circunstancia histórica de conquista, sometimiento y dominación a la que se vio abocado el continente como consecuencia del súbito encuentro de dos realidades opuestas $y$, hasta entonces, ignorantes cada una de la existencia de la otra, se arraigó en estas tierras una errónea idea de superioridad racial de "blancos" sobre "indios"; situación que generó una negación constante por parte de la población mestiza a reconocer sus ascendencias nativas, actitud que persiste hoy en día en un alto porcentaje de la población ecuatoriana, aunque las estadísticas muestran, en los últimos años, una significativa disminución de la misma ${ }^{1}$. La consecuencia de tal actitud ha dado como resultado un vacío identitario dentro de la población ecuatoriana, puesto que la negación de lo indígena implica la no existencia, en el imaginario social, de lo mestizo como tal. En el caso del grupo mestizo ecuatoriano, la negación que de manera consciente se hace de la herencia cultural indígena no aparece de la misma forma en la producción cultural de los mestizos. La mejor prueba de ello está dada por las características del español que se habla en el territorio ecuatoriano marcadamente influenciado por el sustrato quichua.

En este sentido, la música que se hace en el Ecuador es un resultado cultural de este mestizaje, y como tal no escapa a la herencia cultural indígena. En el caso de la música, tanto de "Curare" como de "La Grupa", la dimensión lin- güística se encuentra claramente marcada por esa característica mestiza de dialectización del idioma castellano a través de la incidencia directa del quichua; esto se debe, en parte debido a que los respectivos compositores de cada uno de los grupos musicales pertenece a la comunidad mestiza de la sierra (circunstancia por la cual el dialecto que se puede encontrar en las canciones corresponde más al habla serrana que al resto de regiones), pero también es necesario comprender que existe en ambos grupos una intencionalidad de evidenciar las características lingüísticas de los mestizos, cuyos rasgos propios de pronunciación, semanticidad, etc., suelen ser maquillados cuando los mestizos toman conciencia de ellos ${ }^{2}$.

La sociedad contemporánea, productora y producto de la tan nombrada globalización, está constituida por dos realidades paralelas que coexisten sin que la una niegue a la otra, es decir, por un lado la realidad local, y por el otro la realidad global estereotípica creada por los medios de comunicación masiva, que se han constituido en el vehículo a través del cual se forja nuestra sociedad actual. Las particularidades locales no son anuladas por los estereotipos globales. De las particularidades locales encontradas en la población mestiza de nuestro país se compone la cultura mestiza ecuatoriana.

En algunas canciones, por ejemplo, se evidencian quichuismos lexicales (guambritá), morfológicos, como las inflexiones diminutivas que confieren dulzura y suavidad a las expresiones (morenita), o la forma quichuizada de los "imperativos" en su forma subjuntiva (no te olvidarás...), etc. Asimismo, los dos grupos incluyen en su repertorio canciones que aluden a los aspectos semánticos de la cosmovisión quichua tales como la veneración ancestral a la tierra considerada como madre y mujer, origen de la vida y la cultura.

La cultura no es estática, sino que se encuentra en constante movimiento y transformación. En ese sentido, la mezcla de identidades y de formas culturales ha continuado a través de 
los tiempos. Es decir, que el mestizaje en el Ecuador (y por lo general, en América Latina) no ha terminado de suceder.

Algunas culturas que han originado al mestizo ecuatoriano: españoles (conquista), africanos (esclavitud), medio oriente (líbano), caribe (refugiados colombianos y antillanos), norteamérica (mass media-american way of life; migración - american dream), españoles-italianos-alemanes (fenómeno migratorio). Mezcla de caracteres culturales: Diversificación de manifestaciones artísticas.

\section{Discurso musical y comunicación alternativa}

La música de uno y otro grupo, en realidad tienen más cosas en común de lo que parecería en primer término. Una de ellas es el hecho de que ambos grupos hacen su música a través del formato canción. La otra tiene que ver con el lugar de ambos grupos dentro de la industria. A pesar del discurso que manejan los integrantes de las dos bandas musicales, su música se corresponde directamente con lo que Umberto Eco llama "la canción de consumo".

De esto se desprende el eje de lo que se pretende probar en este apartado de nuestro texto: las implicaciones comunicativas de la música popular están dadas en función de sus características como canción de consumo. El planteamiento de esta cuestión se reviste de vital importancia para los efectos del presente trabajo, en la medida en la que es posible desentrañar la forma en la que la música popular se vale de un plano pedagógico para orientar el mercado y determinar las demandas; pues resulta evidente que ahí están asentadas las bases de los estudios a efectuarse en cuanto a música popular y sus implicaciones comunicativas. En ese sentido, la música popular no es tan sólo una mercancía, un objeto producto del trabajo que se inserta dentro del mercado para ser consumido; sino que, además es un agente pedagógico-comunicativo a través del cual se moldea al mercado.

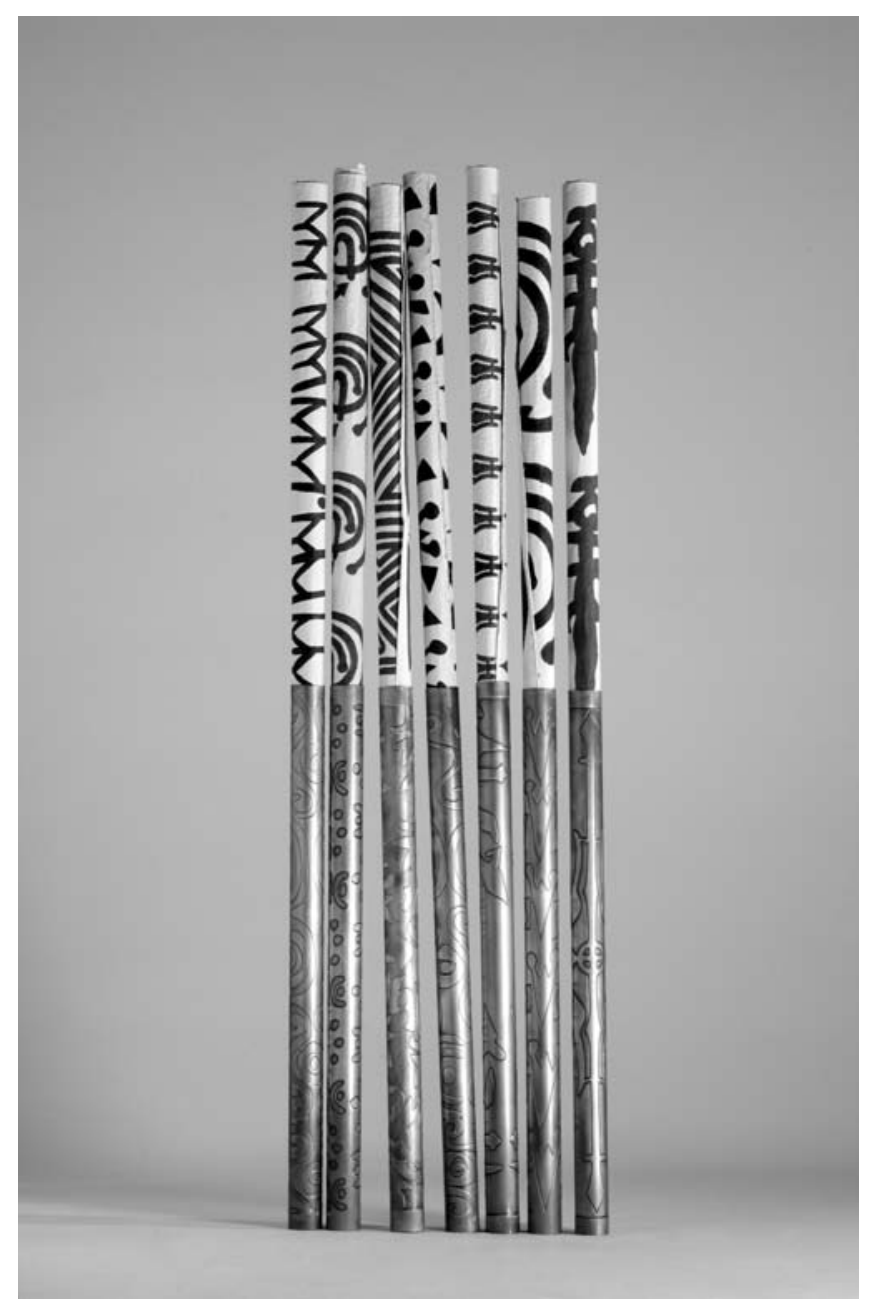

Mi escencia portada

De ahí a afirmar que la música como tal es capaz de funcionar como medio de comunicación solamente hay un paso.

Debido al desarrollo de la música en el contexto de la industria se ha transformado en un fenómeno de masas, y como tal, puede trascender su capacidad intrínseca de lenguaje para convertirse en un medio de comunicación de masas.

Por ello está el que nosotros pensemos que dejar a la música como un mero entretenimiento social es un error garrafal, puesto que implica una limitación atroz de sus posibilidades musicales.

De hecho, las tres funciones fundamentales de los medios de comunicación son: Infor- 


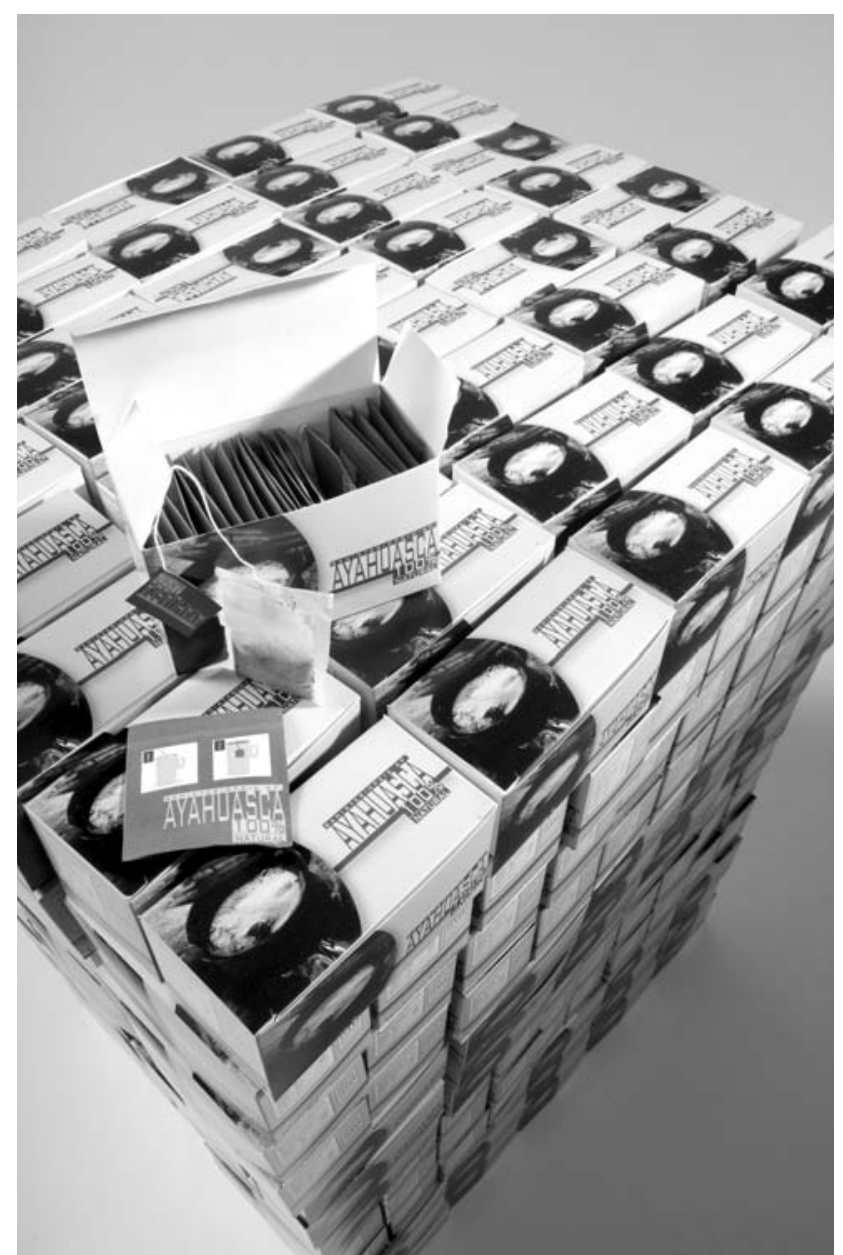

Super depredador

mar, educar y entretener. Esto, solamente si asumimos que los medios de comunicación son de una sola vía. Hemos visto que no es así, y entonces las posibilidades se amplían.

Entonces, la música también puede informar y educar, además de entretener; pero junto con ello, dado que el proceso comunicativo no es unilateral, sino que implica un proceso de doble vía, también moldea la cultura, incluso al mercado y se puede convertir en elemento de integración social, entre otras cosas.

Queda, por tanto, como un deber de los teóricos de la comunicación el realizar estudios más específicos acerca de la música en su contexto co- municativo, y en su posibilidad de medio de comunicación, y es deber de los comunicadores el poner en práctica la teoría, es decir, empezar a utilizar la música con fines estrictamente comunicativos.

Lo que sí nos queda bastante claro es que este tema debe ser manejado con absoluta responsabilidad, ya que la educación de las personas recae, en un alto porcentaje, en los medios de comunicación. Lamentablemente, los medios de comunicación tradicionales, al menos en nuestro país, no han llegado a comprender la gran responsabilidad que tienen. Es necesario delimitar de manera clara hasta dónde llega la "libertad de prensa", y establecer una separación clara entre ésta y la "libertad de opinión y de pensamiento".

Esto debe llevar al establecimiento de una legislación que regule lo que se dice y se muestra en los medios de manera efectiva. Y tal legislación debe abarcar a todos los medios por igual, desde los medios escritos hasta la Internet, pasando, evidentemente, por la música, siempre y cuando sea ésta utilizada con fines única y exclusivamente comunicativos.

Por eso se hacen necesarios posteriores estudios que lleven a desarrollar y ampliar el tema de la música como medio comunicativo. Se necesita que exista una clara diferenciación entre la música como arte puro, la música como mero entretenimiento, y la música como herramienta comunicativa, pues las restricciones no pueden aplicar para los tres casos; únicamente para el último.

\section{Bibliografía}

- ALFARO, Rosa María: Una comunicación para otro desarrollo. $1^{\text {a }}$ ed., Calandria, Lima Perú, 1993.

- BeTteTini, Gian Franco: Producción, significante y puesta en escena. $1^{\text {a }}$ ed., Edit. Lumen, Barcelona - España, 1977.

- CALABRESE Omar: La era Neobarroca, 1a ed. Edit. Cátedra, Madrid - España, 1989. 
- CURARE, Noticias, 2006, www.curarecurare.com

- DE BELLIS, Silvia: Normas de corrección de textos para publicaciones, fecha desconocida, http://www.inta.gov.ar/Sanpedro/info/doc/pdf/Normas correc.pdf.

- ECO, Umberto: Apocalípticos e integrados. $1^{\mathrm{a}}$ ed., Edit. Lumen, Barcelona, España, 1964.

- EL COMERCIO, Los Curare quieren descolonizar el heavy metal a través del "longo metal", Domingo 2 de Mayo de 2004, www.elcomercio.com

- ESPINOZA, Manuel: Los Mestizos Ecuatorianos y las señas de identidad cultural. 2a ed., Edit. Tramasocial, Quito - Ecuador, 1995.

- GARCÍA, Néstor: La dinámica global/local. Cultura y comunicación: nuevos desafíos. $1^{\mathrm{a}}$ ed., Edit.. CICCUS, Barcelona - España, 1999.

- HOCKETT, Charles: "El puesto del hombre en la naturaleza". en Alberto Pereira Valarezo, Lingüística para comunicadores, Datos desconocidos.

- JäGER, Siegfred: "Discursos y conocimiento: aspectos teóricos y metodológicos de la crítica del discurso y del análisis de dispositivos". en Ruth Wodak. Método de análisis crítico del discurso. $1^{\text {a }}$ ed., Gedisa, Edit. Barcelona - España, 2001.

- LÓPEZ, Javier: "El destierro de la música”. El Búho: una revista para lectores, Año V, No 12, Quito, abril/mayo/junio de 2005.

- LÓPEZ, Javier: “Entre Jazz y Agua Larga”. El Búho: una revista para lectores. Año IV, No 16/17, Quito, abril-julio de 2006.

- MALDONADO, Alberto: "Reflexiones sobre la investigación teórica de la comunicación en América Latina”, en Raúl Fuentes (comp.). Comunicación: campo y Objeto de estudio. $1^{\text {a }}$ ed., ITESO, México, 2001.

- MARTÍN BARBERO, Jesús: Deconstrucción de la crítica: nuevos itinerarios de la investigación. Instituto Tecnológico y de Estudios Superiores de Occidente, México 2001.

- MARTÍn BARBERO, Jesús: De los medios a las mediaciones, Edit. G. Gili. S.A. México, 1987.

- MORÍN, Edgar: El Método IV. Las ideas: Su hábitat, su vida, su organización. $1^{\text {a }}$ ed., Edit. Cátedra, Madrid - España, 1992.

- MUlLO, Juan: Nuevas Nociones de identidad musical. Instituto Andino de Artes Populares. Quito, Julio de 2004.

- PRIETO CASTILLO, Daniel: Análisis de mensajes. CIESPAL. Quito, 1988.

- REAL ACADEMIA ESPAÑOLA, Diccionario, 2007, http://buscon.rae.es

- SERRANO, Martín: Teoría de la comunicación. I. Epistemología y análisis de la referencia, 2a. ed., Cuadernos de la comunicación, Madrid - España, 1982.

- TALENS, Jenard: Elementos para una semiótica del texto artístico. $4^{\mathrm{a}}$ ed., Edit. Cátedra, Madrid - España, 1988.

- VASSALLO DE LOPES, María: "Reflexiones sobre la investigación teórica de la comunicación en América Latina", en Raúl Fuentes (comp.) Comunicación: campo y Objeto de estudio. $1^{\text {a }}$ ed., ITESO, México, 2001.

- WIKIPEDIA, Lenguaje, ocho de julio de 2007, http://es.wikipedia.org/wiki/Lenguaje\#Lenguaje visual

- WIKIPEDIA, Mestizaje, 15 de Junio de 2007, http://es.wikipedia.org/wiki/Mestizaje 


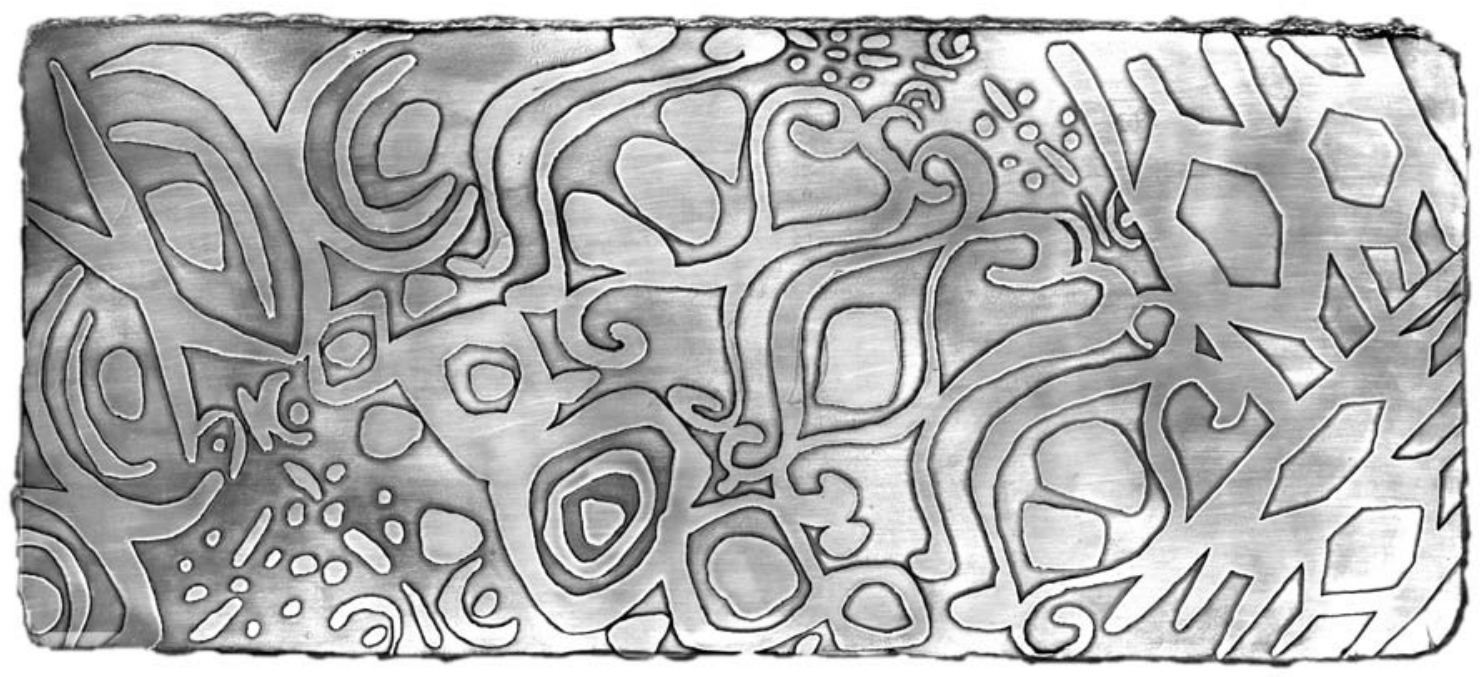

Que respire el aire. Detalle

1 De acuerdo con el estudio realizado por el Proyecto de Opinión Pública de América Latina (LAPOP), publicado en el texto Auditoría de la democracia, Ecuador 2006, editado por CEDATOS, el nivel de identificación étnica de los ecuatorianos con la categoría "mestiza" subió un 5,1\% en un tiempo de cinco años, habiendo, en el año 2001, un 73,6\% de ecuatorianos dispuestos a aceptarse como mestizos, mientras que, para el año 2006, la cifra se encontraba en un $78,7 \%$.

2 Este maquillaje del dialecto se evidencia de manera clara en el migrante. Durante los últimos años, el fenómeno migratorio ha tenido como destino a países europeos, siendo España el país que más migrantes ecuatorianos ha recibido. Una curiosidad del fenómeno está dada por el hecho de que, cuando estos migrantes retornan a su país natal, llegan tratando de imitar el acento, las expresiones, la pronunciación y demás características lingüísticas propias de los españoles, a través de lo cual consiguen establecer una distinción social superior de quienes no han salido de su tierra y los reciben a su regreso. 